\title{
Parenting Beliefs and Achievement Pressure of Korean Mothers with Five to Seven Year Old Children According to Child's Gender, Mother's Education Level, and Employment Status
}

This study examined the parenting beliefs and the achievement pressure of Korean mothers with five to seven year old children. The maternal parenting beliefs criterion (Ahn, 2001) and achievement pressure criterion (Hong, 2001) have been applied to 212 mothers living in Seoul or KyonggiDo area and analyzed. The results showed that the maternal parenting beliefs were influenced by the child's gender, while the maternal achievement pressure was not. And significant difference was seen only in between the educational background and the maternal parenting beliefs, and the employment status and interaction effects were not shown.

The Barack Obama Administration has shown a continuous interest in education conscious Korean parents. The United States Secretary of Education, Arne Duncan has stated that Korean parents demand a great deal from education, and both the President and the government hope American

\footnotetext{
*Assistant professor, Department of Child Studies \& Education, Hanyang Cyber University, Korea (4100025@hycu.ac.kr)

${ }^{*}$ Visiting Scholar, Department of Education, The University of Georgia, USA (kgsqueen72@gmail.com)

***Part-time Lecturer, Department of Living Culture Studies, The Catholic University, Korea

Key Words: parenting beliefs, achievement pressure, child's gender, mother's education level, mother's employment status
}

parents ask demands related to education (Chosunilbo, 2010). The reason that America has a national interest in the educational consciousness of Korean parents is due to the superb scholastic achievements of Korean students (National Center for Education Statistics Trends, 2000) and the high quality human resource pool that directly influences national growth.

Educational consciousness is related to parenting beliefs, defined by, "a combination of nurturing intentions and knowing the methods" and "the recognition of child- nurturing as truth" (Ahn, 2003; Lee, 2007). Parenting beliefs are known to have a direct influence on parenting behavior and are constant since they are founded on knowledge, information, and personal experiences (Lee, 2007; McGillicuddy-DeLisi, 1985; Sigel, 1985). Parenting beliefs represent a comprehensive concept that is subdivided into the development principles, goals, and values of child nurture, and parenting role principles (Luster \& Rhoades, 1989; Okagaki \& Divecha, 1993; Okagaki \& Sternberg, 1993). A majority of research in Korea has focused on the believes that, "Putting emphasis on intellectual achievement or personality development (personality development accentuation/intellectual achievement accentuation principle)" and "seeing that child development is influenced by natural growth or 
intervened by environmental factors (natural growth/environmental principle)" (Ahn, 2001; Ahn, 2003; Kim \& Ohm, 2007; Lee, 2007). Early research on Korean mothers from 1980 1990s showed that mothers underemphasized citizenship, fairness, and practicality (Korea Gallup, 1980) and focused on scholastic competitions (Hyun, Kong, Kim, \& Lee, 1997), high-class schools, and acquiring socially recognized positions and careers. This states that Korean mothers tend to prioritize the intellectual development of children through education from an environmental standpoint. Research starting in the year 2000 shows that mothers place a priority on the intellectual development of a child over personality development, subsequently, they tend to identify environmental stimulation over maturity, as a key factor in the development of a child (Kim, 2009; Shin, 2011). However, there are opposing results that place a priority on personality development over intellectual development (Ahn, 2001; Kim \& Ohm, 2007; Kim, 2011; Lee, 2010), and child development that results from maturity (Kim, 2011). There have been recent demands by parents for a naturefriendly and communal lifestyle, and increase of alternative schools, an atypical education style focused on learners, and professional schools (Jung \& Lee, 2012). The changes indicate the further need for additional research on the parenting beliefs of contemporary mothers.

Parenting beliefs differ in relation to the gender of the offspring and the educational background and employment status of the parents. Parents emphasize fulfillment and cognitive ability towards sons versus obedience towards daughters (McGillicuddy-DeLisi, 1985; Okagaki \& Sternberg, 1993). Research on Korean mothers shows that they stress personality development and a maturity principle towards boys versus intellectual achievement and environmental principles on girls. This is a difference in parenting principle according to gender (Lee, 2010). The education-level of mothers shows a significant variation, based on those who have obtained graduate degrees or above university level education, place personal maturity as a key to their child's education, place group over individual, and personality over intellect (Lee, 2007). There are studies that suggest a high maternal education level that emphasize personality development (Lee, 2010) versus other research that emphasize intellectual development (Ko, 2001; Kim \& Ohm, 2007). Researches by Kim's (2009) and Moon's (2008) show that a higher mother's education level results in a higher emphasis of independence over obedience, and reinforces the idea that the mother's education level is an important factor for the determination of parenting beliefs. However, a clean conclusion is yet to be provided due to inconsistency in the results. The employment status of the mother is related to her parenting beliefs. Shin (2011) and Jeong (2003) reported on unemployed mothers who have a childcentered educational view and believe that development occurs through inner maturity, in contrast to employed mothers. Full-time mothers have stronger desires for intellectual achievement compared to employed mothers (Ahn, 2001; Kim, 2009). Meanwhile, the research by Lee (2007) show that the mother's employment status and parenting beliefs are independent of each other and show that the two are different matters.

Achievement pressure is defined as the children's perception of parental involvement in education, achievement and role expectations (Kang, 2003; Luthar \& Latendress, 2005), in addition, it is a factor of parental behavior directly influenced by parenting beliefs (Ahn, 2003). Mothers tend to expect their children to behave in a perfect manner, through providing private education, checking grades and test results from school, and limiting free time of their children, however, children recognize these parental behaviors as expectations and academic achievements stimulus (Hong, 2001; Luthar \& Becker, 2002).

Achievement pressure from parents can have a positive and negative effect. The positive effects of achievement pressure show a high achievement motivation, self-efficacy (Ku, 2008; Park, Kim, \& Chung, 2004; Yonezawa, 2000), and high academic grades (Choo \& Lim, 2008; Smith, Beaulieu, \& Seraphine, 1995), however, excessive achievement pressure could instigate problems. High expectations for children's achievements results in high stress levels (Ang \& Huan, 2006). Excessive pressure from 
parents can block the child's capabilities, decrease their interests and values (Levine, 2006), and result in depression and physical pain (Hardy, 2003). Many studies show a consistency in the achievement pressure by Korean mother to be abnormal (Hong \& Lee, 2012; Kim, 2009). These studies have mainly concerned parents with elementary, middle and high school children, however, more research is required on parents with kindergarteners.

Specialized research on parenting beliefs and achievement pressure by parents with kindergartener limited even after the proposition of the 'Parenting Beliefs Parenting Behavior' model (Sigel, 1985). Oh and Jung (2006) suggested a higher level of achievement pressure due to increase parenting beliefs that emphasize acquirable factors such as intellectual achievement and higher education for mothers. The research by Greenberger, Lessard, Chen and Farruggia (2008) on university students, showed that mothers with a high level of achievement pressure prioritize their children's intellectual achievements. Other research on mothers of kindergarteners showed that mothers with high level of achievement pressure emphasize intellectual achievement and stress environmental influence.

The mother's achievement pressure indicates differences based on child's gender, the mother's education level, and the mother's employment status. Research by Kim (2008) showed that sons were more aware of their mother's achievement pressure than daughters. Researches by Jung (2004) and Park and Chong (2010) showed that mothers focused achievement pressure more towards sons. The study by Han (2008) showed that vocational college graduate mothers had the highest achievement pressure, university graduates second, and high school graduates next. Employed mothers apply higher achievement pressure versus those unemployed (Go, 2002), reciprocally, a child of an employed mother received more private education and showed a higher achievement pressure (Han, 2008). The research results show the difference in achievement pressure according to child's gender, mother's employment status, and mother's education background, however, the research is limited on parents with kindergartener.
There is limited research on kindergartner's parents, therefore, it is essential to investigate the tendency of parenting beliefs and achievement pressure, the parenting beliefs and achievement pressure relation, and parenting beliefs and achievement pressure differences according to child's gender, mother's education level, and mother's employment status.

The proposed research questions are as follow:

1. How are mother's parenting beliefs and achievement pressure?

2. What is the relation of the mother's parenting beliefs and achievement pressure?

3. Are there differences in the mother's parenting beliefs and achievement pressure according to the child's gender?

4. Are there differences in the mother's parenting beliefs and achievement pressure according to the mother's educational background and employment status?

\section{METHODS}

\section{Participants and Procedures}

Parents and caregivers of subjects from ages five to seven at two kindergartens were preliminarily investigated from January $20^{\text {th }}$ to January $22^{\text {nd }}, 2010$ to measure the ambiguity of the questionnaire and the time cost to run the tests. The pre-test took approximately 30-40 minutes to complete the questionnaire and there was no difficulty to understand the questions. The tests were given to 212 parents and caregivers of children, aged five to seven from three kindergartens located in Seoul and one kindergarten in Kyonggi-Do. The questionnaire was delivered directly or by mail, and certified teachers at each institution delivered and collected them. A total of 213 questionnaires were collected, however, achievement-pressure questions were not completed in one of the questionnaires and left 212 questionnaires for the final analysis.

The analysis included 212 children (113 male and 99 females), from 66 to 92 months old with an the average age of 79 months. The average age of male and females were the same, however, male 
Table 1. Demographic Characteristics of Participants $(N=212)$

\begin{tabular}{|c|c|c|c|c|c|c|}
\hline & \multicolumn{4}{|c|}{ Category } & \multirow[t]{2}{*}{ Frequency } & \multirow[t]{2}{*}{$\%$} \\
\hline & & & Mean & Range & & \\
\hline \multirow{3}{*}{ Child } & \multirow{3}{*}{ Year (Months) } & Male & 79 & $66-92$ & 113 & 53.3 \\
\hline & & Female & 79 & $72-91$ & 99 & \multirow[t]{2}{*}{46.7} \\
\hline & & Subtotal & 79 & $66-92$ & 212 & \\
\hline \multirow{17}{*}{ Mother } & Year (Age) & & 36.92 & $30-49$ & & \\
\hline & \multirow{4}{*}{ Educational Level } & \multicolumn{2}{|c|}{ High School } & & 55 & 25.9 \\
\hline & & \multicolumn{2}{|c|}{ Two Year College } & & 53 & 25.0 \\
\hline & & \multicolumn{2}{|c|}{ Four Year College } & & 94 & 44.3 \\
\hline & & \multicolumn{3}{|c|}{ Graduate School or Above } & 10 & 4.7 \\
\hline & & \multicolumn{3}{|c|}{ Self-employed } & 8 & 3.8 \\
\hline & & \multicolumn{3}{|c|}{ Professional Career } & 28 & 13.2 \\
\hline & $C$ & \multicolumn{3}{|c|}{ Company Employee } & 23 & 10.8 \\
\hline & Cuirentil Vecupationi & \multicolumn{3}{|c|}{ Service Industry Employee } & 2 & 0.9 \\
\hline & & \multicolumn{3}{|l|}{ Others } & 9 & 4.2 \\
\hline & & \multicolumn{3}{|c|}{ Housewife } & 142 & 67.0 \\
\hline & & \multicolumn{3}{|c|}{ Below One Million Won } & 1 & 0.5 \\
\hline & & \multicolumn{3}{|c|}{ One to Two Million Won } & 11 & 5.2 \\
\hline & Mo th & \multicolumn{3}{|c|}{ Two to Three Million Won } & 61 & 28.8 \\
\hline & DVivinity & \multicolumn{3}{|c|}{ Three to Four Million Won } & 70 & 33.0 \\
\hline & & \multicolumn{3}{|c|}{ Four to Five Million Won } & 32 & 15.1 \\
\hline & & \multicolumn{3}{|c|}{ Over Five Million Won } & 37 & 17.5 \\
\hline
\end{tabular}

children had a range from 66 to 92 months old, and female children had a range from 72 to 91 months old. The demographic background of mothers showed that the average age was 36 years 11 months and ranged from 30 to 49 years old. The educational background showed that university graduates were 94 (44.3\%), 55 high-school graduates (25.9\%), 53 vocational college graduates $(25.0 \%)$, and 10 postgraduate school graduates or above (4.7\%). Their current occupations were listed as 142 housewives (67.0\%), 28 professional career women (13.2\%), 23 company employees $(10.8 \%), 8$ self-employed (3.8\%), 2 service industry employees $(0.9 \%)$, and 9 others (4.2\%). A total of 70 people $(33.0 \%)$ had three to four million won as their monthly-income, 61 people $(28.8 \%)$ earning two to three million won, 37 people $(17.5 \%)$ earned over five million won, 32 people $(15.1 \%)$ earned four to five million won, 11 people (5.2\%) earned one to two million won, and 1 person $(0.5 \%)$ earned less than one million won.

\section{Measures}

Maternal Parenting Beliefs Prior research and questionnaires such as, Ahn's (2001) and Lee's (1983) “Child education principle", Kim’s (1996) “Traditionalmodern maternal values", and Segal's (1985) "Maternal Beliefs and Values Q-sort" (Luster \& Rhoades, 1989; Okagaki \& Sternberg, 1993; Sameroff $\&$ Feil, 1985) were used as references. There are 32 questions for children's mothers to answer. Each question has one to seven criteria, the rated scale is from 32 to 224 points. The questions are designed for the respondent to choose a side that coincides with their opinions, formally known as the constrained multiple-criteria method. Low points indicate that the maternal view stresses the development of personalities through maturity, however, high points indicate a maternal view that 
Table 2. Mean and Standard Deviation of Maternal Parenting Beliefs and Achievement Pressure $(N=212)$

\begin{tabular}{lcccc}
\hline & M & SD & Question M & SD \\
\hline Parenting beliefs & 114.20 & 17.56 & 3.57 & 0.55 \\
Achievement pressure & 69.74 & 10.74 & 3.49 & 0.54 \\
\hline
\end{tabular}

emphasized intellectual development through an environmental position. This questionnaire was constructed for respondents to choose an answer that is closer to their beliefs from questions, such as 'I would rather like my child to be better academically focused than personality focused. - I would rather like my child to the better personality focused than academically focused, 'Children develop with their innate characteristics. - Child development is more influenced by maternal behavior.' The sum of the item internal consistency was 0.73 .

Maternal Achievement Pressure Maternal achievement pressure was used the achievement pressure criteria of Hong (2001). The questionnaire is composed of 20 items, each question have one to five criteria, and the rated scale is from 20 to 100 points in total. High points indicate high maternal achievement pressure rates. The questionnaire consists of questions, such as 'I do not like my children to cancel private tutoring classes due to their friends,' 'I think I will check my children's academic schedule even after they achieve a higher grade,' 'I will restrict their free time with friends.' The sum of item internal consistency was 0.90 .

\section{Data analysis}

Each measurable factor was numerically calculated by mean and standard deviation methods to examine the general tendency of the maternal parenting beliefs. A Pearson's coefficient of correlation was used to investigate the relation of maternal parenting beliefs and achievement pressure, in addition, $t$-test and two-way ANOVA investigated parenting beliefs and achievement pressure differences according to the maternal factor and child's gender.
Table 3. Correlation Coefficient of Maternal Parenting Beliefs and Achievement Pressure $(N=212)$

\begin{tabular}{lc}
\hline & Achievement pressure \\
Parenting beliefs & $.42^{* *}$ \\
\hline$* * p<01$. &
\end{tabular}

\section{RESULTS}

General Tendency of Maternal Parenting Beliefs and Achievement Pressure

Table 2 presents mean, question mean and standard deviation to show the general tendency of maternal parenting beliefs and achievement pressure. The results of maternal parenting beliefs show that the mean and the question mean are $114.20(\mathrm{SD}=17.56)$ and $3.57(\mathrm{SD}=0.55)$ respectively. In the case of achievement pressure, the results show that they are $69.74(\mathrm{SD}=10.74)$ and $3.49(\mathrm{SD}=0.54)$. The results of the question mean show that the parenting beliefs rates are $3.57(\mathrm{SD}=0.55)$ out of 7 , slightly lower than 4 , however, the achievement pressure rates are 3.49 $(\mathrm{SD}=0.54)$ out of 5 , mostly in the middle of "average" and "slightly agree".

\section{Relationship between Maternal parenting beliefs and Achievement Pressure}

Table 3 shows the numeric value of $r=.42(p<.01)$, and is a high counter-affinity relationship between maternal parenting beliefs and achievement pressure, where the maternal parenting beliefs rate increases, along with the achievement pressure rate. The mothers desire for intellectual development of their child is strong, and those on the environmental side value the achievement pressure more significantly.

\section{Maternal parenting beliefs and Achievement Pressure influenced by Child's Gender}

Table 4 shows if a child's gender influences maternal 
Table 4. Child Gender's Influence on Maternal Parenting Beliefs and Achievement Pressure's Mean, Standard Deviation and T-Value $(N=212)$

\begin{tabular}{|c|c|c|c|c|c|}
\hline & \multicolumn{2}{|c|}{ Male $(n=113)$} & \multicolumn{2}{|c|}{ Female $(n=99)$} & \multirow{2}{*}{$t$} \\
\hline & M & SD & M & $\mathrm{SD}$ & \\
\hline Parenting beliefs & 116.46 & 17.11 & 111.63 & 17.80 & $2.01 *$ \\
\hline Achievement pressure & 69.82 & 11.28 & 69.64 & 10.14 & .12 \\
\hline
\end{tabular}

Table 5. Education Level and Employment Status of Mothers Influencing Maternal Parenting Beliefs and Achievement Pressure's Mean \& Standard Deviation $(N=212)$

\begin{tabular}{|c|c|c|c|c|c|}
\hline & & & Frequency & $\mathrm{M}$ & $\mathrm{SD}$ \\
\hline \multirow{4}{*}{ Parenting beliefs } & \multirow{2}{*}{ Education level } & Below two years college & 108 & 117.22 & 16.21 \\
\hline & & Over four years college & 104 & 111.07 & 18.42 \\
\hline & \multirow{2}{*}{ Employment status } & Employed mother & 70 & 113.43 & 18.16 \\
\hline & & Housewife & 104 & 114.59 & 17.32 \\
\hline \multirow{4}{*}{ Achievement pressure } & \multirow{2}{*}{ Education level } & Below two years college & 108 & 70.07 & 9.88 \\
\hline & & Over four years college & 104 & 69.40 & 11.60 \\
\hline & \multirow{2}{*}{ Employment status } & Employed mother & 70 & 71.29 & 11.38 \\
\hline & & Housewife & 104 & 68.98 & 10.37 \\
\hline
\end{tabular}

parenting beliefs and achievement pressure. Maternal parenting beliefs were influenced by the child's gender $(t=2.01, p<.05)$, however, maternal achievement pressure was not. The table shows that higher points of the mother influence the intellectual development of sons over daughters in regards to the environmental attitude.

\section{Maternal Attribute's (Education, Employment Status) Influence on Maternal Parenting Beliefs and Achievement Pressure}

Table 5 shows the mean and standard deviation of maternal parenting beliefs and achievement pressure in regards to mothers' education and employment status.

In the case of parenting beliefs, individuals below a vocational college education were 117.22 points $(\mathrm{SD}=16.21)$ out of 224 points in total, however, university graduates scored 111.07 points $(\mathrm{SD}=$ 18.42) out of 224 points. In accordance with employment status, employed mothers scored 113.43 points $(\mathrm{SD}=18.16)$, housewives scored 114.59 points $(\mathrm{SD}=17.32)$; housewives had higher scores than employed mothers in regards to parenting beliefs.
For parenting beliefs, those with a vocational college education had a higher mean score than mothers with a university education, in addition, housewives had higher mean score than employed mothers.

Education and employment status showed scores in the case of achievement pressure. Those with education including and lower than vocational college degrees scored 70.07 points $(S D=9.88)$ out of 100 points, and was slightly higher than university graduates or above $(\mathrm{M}=69.40, \mathrm{SD}=11.60)$. Those who were employed scored 71.29 points $(\mathrm{SD}=11.38)$, and was slightly higher than housewives $(\mathrm{M}=68.98$, $\mathrm{SD}=10.37$ ).

A two-way ANOVA (See Table 6) surveyed statistical differences. Table 6 shows significant differences $(F=4.65, p<.05)$ between education background and maternal parenting beliefs, however, the employment status and interaction effects were not identified. Mothers with a vocational college or lower scored higher parenting beliefs points compared to those who had a university education or higher. This implies that those with lower educational background give priority in intellectual development and have an environmental standpoint. 
Table 6. Two-way ANOVA of Education Background and Employment Status of Mothers Related to Maternal Parenting Beliefs and Achievement Pressure $(N=212)$

\begin{tabular}{llrrrr}
\hline & Depending variable & $d f$ & \multicolumn{1}{c}{ MS } & \multicolumn{1}{c}{$S S$} & \multicolumn{1}{c}{$F$} \\
\hline \multirow{2}{*}{ Education background } & Parenting beliefs & 1 & 1407.48 & 1407.48 & $4.65^{*}$ \\
& Achievement pressure & 1 & 23.02 & 23.02 & .20 \\
\hline \multirow{2}{*}{ Employment status } & Parenting beliefs & 1 & 13.13 & 13.13 & .04 \\
& Achievement pressure & 1 & 261.16 & 261.16 & 2.26 \\
\hline Education background & Parenting beliefs & 1 & 129.99 & 129.99 & .43 \\
Employment status & Achievement pressure & 1 & 17.99 & 17.99 & .16 \\
Error variance & Parenting beliefs & 208 & 302.67 & 62954.77 & \\
& Achievement pressure & 208 & 115.47 & 24018.21 & \\
\hline
\end{tabular}

${ }^{*} p<.05$.

\section{DISCUSSION}

This study investigated the tendency of parenting beliefs and achievement pressure, the relation between parenting beliefs and achievement pressure, and the differences in parenting beliefs and achievement pressure according to the child's gender, mother's education level and employment status.

The general tendency of Korean mother's parenting beliefs showed favoritism towards the maturity principle over the environmental principle. This can be meant that Korean mothers believe that they will naturally mature as a child ages, in addition, the results of achievement pressure scored slightly higher than the median value. Thus, mothers tend to emphasize the intellectual achievement of children and think it is necessary to provide educational environment and direction. This shows that Korean mothers can experience confusion from the mismatch of principle and attitude because of the distinctive characteristics of Korean society. Korean mothers must emphasize the achievement pressure on their child even though they value personality development and know that patience is required to develop a child's personality. By providing a chance to change our perceptions through debating over credentialism and seeking institutional plans, the realization of personality-development focused maternal value system is in quick reach.

The relation between maternal parenting beliefs and achievement pressure showed an attentive positive correlation. Mothers orientated towards the environmental belief, emphasize intellectual/academic achievements and provide further educational stimulus. This corresponds to the research results of Oh \& Jung (2006), Greenberger et al., (2008) and Ahn (2003). Hong (2001) suggested kindergartener parent's achievement pressure tends to exhibit behavior, such as limiting playtime, and values private education more than play, however, these actions can have a negative influence on the child because of the importance of playtime in child development. Therefore, abnormally high level of achievement pressure needs to be adjusted along with cases that include environmental parenting beliefs. Parent education programs appeal to the importance of play in childhood would be helpful for the environmental views that emphasize academic and intellectual achievements, as well as those that influence child growth through achievement pressure and excess, or facilitate the child's development.

An examination of parenting beliefs and achievement pressure according to the child's gender show that Korean mothers emphasize intellectual achievement for sons, however, there was no gender bias in terms of achievement pressure. Differences in parenting beliefs and achievement pressure according to child's gender coincide with the research results of Lee (2010), Luster and Okagaki (1993). The deeply rooted influence of Confucianism in Korean culture could be one of the reasons for these differences. Korea has been under influence by Confucian culture for a long period and has formed a 
patriarchal society. These aspects and ideas have been abolished in 1970's national campaigns, however, academic and social successes seem to be still focused on sons over daughters, while pressure towards the acquisition of intelligence does not differ by gender. Results for achievement pressure having no distinct relation in gender difference and correspond to the research results of Luthar \& Becker (2002), and likely explain the increased entry of women into public affairs. Female's university/ college admission and economic activities have increased. The female's university/college entrance rate is $80.5 \%$, and economic activity rate is $51.3 \%$ (Korean Statistical Information Service, 2011). As more women enter college/university and public affairs show that mothers place the same level of achievement pressure on daughters as sons.

This study examined the disparity in parenting beliefs based upon the mother's education level and employment status. In the results, mothers with college education or lower have a stronger belief towards environmental principles over mother's with a university education or higher, while employment status was not influential. Those with high a level of education oriented their children towards maturity development through sharing, rather than commanding them. This corresponds to previous studies, where children are desired to be voluntary and active, instead of pliable and passive (Lee, 2007; Schaefer \& Edgerton, 1985). This phenomenon can be interpreted by the mother's self-confidence and high sense of capability in raising children (Kwon, 2009). In other words, mother with high academic background waits for their children to learn from experiences instead of forcing early education on their children because they are confident in their ability to help whenever their children have failed or make a mistake. Excessive environmental parenting beliefs views are shown by the increased nurturing capabilities of parents. This research initially thought that individual career status could influence parenting beliefs, however, there was no significant finding in the variance of employment status and parenting beliefs. According to Hess, Kashiwagi, Azuma, Price, \& Dickson (1980), Asian mothers tend to emphasize child nurturing over personal accomplishments and careers. Especially, Korean mother's parenting beliefs are resolute. Many Korean mothers quit their jobs after giving birth, thinking "children should be raised by mothers" (Park, 2003). This seems to be a reason for the non-difference between employment status and parenting beliefs.

Lastly, this research was investigated the achievement pressure difference due to the educational background and employment status of the mother, however, there were no statistical significant difference found in the two. This is a contradictory result to the research by Go (2002) and Han (2008). This study showed differences from their researches in the employed mother's job type and the categorization of mother's education level, however, these results could not be concluded and only inferred. Therefore the reasons whether they come from mother's job type or categorization of mother's education should be investigated in further research.

Even though these results are meaningful, there are some limitations to the results of this study. Data collection was done in Seoul and Kyonggi-Do, which are the most advanced districts in Korea. Thereby, this is likely to be reflected the regional characteristics. Therefore further study which would include mother and child of the other districts should be followed. Also, Measurement tools were questionnaires reported by mother. Questionnaire is easier and more cost-effective in data collection, however it is not outside the realms of possibility that respondents may tend to answer desirable responses. So, evaluation by observation needs to be done together. Suggestions for further studies are as follows. This study revealed the possibility that Koreas Confucianism and rapidly increasing entry of women in public affairs may be related to the mother's parenting beliefs and achievement pressure, therefore, if it is explored the effects of these factors influencing to maternal parenting beliefs and achievement pressure, it would be meaningful research. Furthermore, the study also compared with the parenting beliefs and the achievement pressure of Korean mothers and foreign mothers is considered to be meaningful. Despite these limitations, this study is important because it illustrates the trends of maternal parenting beliefs and achievement pressure of Korean mothers 
with five to seven year old children.

\section{REFERENCES}

Ahn, J. Y. (2001). The effects of maternal parental beliefs, efficacy and stress on mother's parenting behaviors. Unpublished doctoral dissertation, Ewha Women's University, Seoul, Korea.

Ahn, J. Y. (2003). The relationship between current trend of early education and maternal parental beliefs, stress, and achievement pressure. Journal of the Korean Home Economics Association, 41(11), 95-111.

Ang, R. P., \& Huan, V. S. (2006). Relationship between academic stress and suicidal ideation: Testing for depression as a mediator using multiple regression. Child Psychiatry Human Deviant, 37, 133-143.

Choo, S. Y., \& Lim, S. M. (2008). The relationship between parental achievement pressure and high school students' academic achievements: The mediating effects of parental involvement and academic self-efficacy, and the moderating effect of academic procrastination. Korea Journal of Youth research, 15(7), 347-368 .

Chosunilbo (2010, October 22). U.S. secretary praises Korean education. Chosunilbo. Retrieved May 20, 2012, from http://english.chosun.com/site/data/html_ $\operatorname{dir} / 2010 / 10 / 22 / 2010102200924 . h t m l$

Go, H. J. (2002). The effects maternal employment on the maternal child-rearing attitude perceived by child and child's self-concept. Unpublished master's thesis, Chenbuk National University, Cheonju, Korea.

Greenberger, E., Lessard, J., Chen, C., \& Farruggia, S. P. (2008). Self-entitled college students: Contributions of personality, parenting, and motivational factors. Journal of Youth $\mathcal{E}$ Adolescence, 37, 1193-1204.

Han, S. M. (2008). Young children's behavioral problems according to their participation in private activities and mother's achievement pressure. Unpublished master's thesis,Yonsei University, Seoul, Korea.

Hardy, L. (2003). Overburdened, overwhelmed. American School Board Journal, 190(4), 18-23.

Hess, R., Kashiwagi, K., Azuma, H., Price, G., \& Dickson, P. (1980). Maternal expectations for mastery of developmental tasks in Japan and the United
States. International Journal of Psychology, 15, 259-271.

Hong, E. J. (2001). A study on the effects of dependence upon institutes and home study paper by mothers' accomplishment-oriented pressure upon their young children's stress. Unpublished master's thesis, Ewha Women's University, Seoul, Korea.

Hong, Y. J., \& Lee, J. Y. (2012). Mediating Effects of Parental Learning Involvement and Academic SelfEfficacy of Elementary School Students between Parental Academic Achievement Pressure and Academic Achievement. The Journal of Child Education, .21(2), 325-342.

Hyun, O. K., Kong, I. S., Kim, Y. J., \& Lee, W. J (1997). The present state and perception of worksheets for young children. Korean Journal of Child Studies, 18(2), 213-228.

Jeong, H. I. (2003). The relationship between maternal parenting beliefs and efficacy, and children's daily stress. Unpublished master's thesis, Ewha Women's University, Seoul, Korea.

Jung, I. L., \& Lee, H. N. (2012, June 6). Can expanding alternative schools help the suffocating public education. Sisa journal. Retrieved July, 20, 2012. From http://www.sisapress.com/news/articleView. html?idxno $=58030$

Jung, S. H. (2004). The relationship among perceived academic achievement pressure put by parents, scholastic competence perception, ego-resiliency, and stress of pupil. Unpublished master's thesis, Changwon National University, Changwon, Korea.

Kang, Y. C. (2003). On the relationship among the parents' academic achievement pressure recognized by the elementary pupils, their academic self and their attitude toward it. Unpublished master's thesis, Changwon National University, Changwon, Korea.

Kim, B. R., \& Ohm, J. A. (2007). The relationship between the actual state of extra curricula education for kindergarteners and maternal beliefs regarding child rearing. Journal of the Korean Home Economics Association, 45(8), 13-24.

Kim, J. S. (1996). Mother's traditional-modern values in nurturing behavior and child's social behavior. Unpublished doctoral dissertation, Ewha Women's Uni- 
versity, Seoul, Korea.

Kim, M. J. (2008). The effect of parental nurturing attitude on children's self-concept. Unpublished master's thesis, Kawndong University, Gangwon, Korea.

Kim, M. J. (2011). The effect of mother's parenting beliefs and expectation on parenting intelligence. Korean Journal of Family Welfare, 9(3), 155-170.

Kim, M. R. (2009). The effect of middle school students' perceived achievement pressure and empathy ability on psychological well-being and prosocial behavior. Unpublished master's thesis, Hanyang University, Seoul, Korea.

Kim, S. Y. (2009). The relationship between mother's parental beliefs and their child-rearing behaviors. Korean Journal of Human Ecology, 18(2), 313-324.

Ko, Y. H. (2001). Demographic variables and the relations between maternal beliefs and child-rearing behaviors : a focus on mothers of 2-to 3-year-old children. Unpublished master's thesis, Ewha Women's University, Seoul, Korea.

Korea Gallup (1980). Korean child and mother. Opinion of Koreans, Series I. Seoul: Korea Gallup.

Korean Statistical Information Service (2011). Statistics on women's lives. Seoul: Korea Development Institute.

$\mathrm{Ku}, \mathrm{H}$. G. (2008). The effects of maternal achievement pressure and emotional support on adolescents' achievement motivation. Unpublished master's thesis, Ewha Women's University, Seoul, Korea.

Kwon, H. K. (2009). The relations of father's participation in the care of their children, mother's parenting behavior, mother's parenting efficacy, and learning-related social skills of children. Korean Journal of Early Childhood Teacher Education, 13(4), 7998.

Lee, J. H. (2010). A study on maternal belief and preschooler's multiple intelligences. Unpublished master's thesis, Sookmyung Women's University, Seoul, Korea.

Lee, J. S. (2007). The relationship between maternal childrearing beliefs, achievement pressure and trends in early $\mathcal{E}$ speciality education for their children. Unpublished master's thesis, Kongju National University, Kongju,
Korea.

Lee, W. Y. (1983). The relationship of mothers educational view and child - rearing attitudes to child development. Korean Journal of Early Childhood Education, 5, 101-140.

Levine, M. (2006). The price of privilege: how parental pressure and material advantage are creating a generation of disconnected and unhappy kids. NY: HarperCollins.

Luster, T., \& Okagaki, L. (1993). Multiple influences on parenting: ecological and life-course perspective. Hillsdale, NJ: Lawrence Erlbaum Associates.

Luster, T., \& Rhoades, K. (1989). The relation between child rearing-beliefs and the home environment in a sample of adolescent mothers. Family Relations, $38,317-322$.

Luthar, S. S., \& Becker, B. E. (2002). Privileged but pressured: A study of affluent youth. Child Development, 73, 1593-1610.

Luthar, S. S., \& Latendresse, S. J. (2005). Children of the affluent: Challenges to well-being. Current Directions in Psychological Science, 14, 49-53.

McGillicuddy-DeLisi, A. V. (1985). The relationships between parental beliefs and children's cognitive level, In. I. E. Sigel (Ed.), Parental belief systems: the psychological consequences for children (pp. 7-24). Hillsdale, NJ: Lawrence Erlbaum Associates.

Moon, S. J. (2008). A study of parental beliefs and children's self control. Unpublished master's thesis, Sookmyung Women's University, Seoul, Korea.

National Center for Education Statistics Trends. (2000). TIMSS 1999 achievement report: mathematics/science. Washington DC: National Center for Education Statistics Trends.

Oh, J. Y. \& Jung, T. Y. (2006). Variation in Mother's Parenting Style Dependent on Their Children's school Age. The Journal of School Psychology, 3(2), 4354 .

Okagaki, L., \& Divecha, D. J. (1993). Development of parental beliefs. In. T. Luster, \& L. Okagaki, (Eds.), Parenting: an ecological perspective(pp. 35-67). Hillsdale, NJ: Lawrence Erlbaum Associates.

Okagaki, L., \& Sternberg, R. J. (1993). Parental beliefs 
and children's school performance. Child Development, 64, 36-56.

Park, S. M. (2003). The longitudinal research on the Korean women`s second labor market transition. Korean Journal of Women Studies, 19(1), 43-80.

Park, S. Y., \& Chong, Y. S. (2010). Moderating Effects of Ego-Resilience and Social Support in Relations among Academic Achievement Pressure, Perceived Academic Stress and Internalization Problems in Boys and Girls. The Korean Journal of Developmental Psychology, 23(1), 17-32.

Park, Y. S., Kim, U. C., \& Chung, K. S. (2004). Longitudinal analysis of the influence of parent-child relationship on adolescents' academic achievement: with specific focus on the mediating role of self-efficacy and achievement motivation. Korean Journal of Psychological and Social Issues, 10(3), 37-59.

Sameroff, A., \& Feil, L. (1985). Parental concepts of development. In. I. E. Sigel (Ed.), Parental belief systems: the psychological consequences for children. Hillsdale, NJ: Lawrence Erlbaum Associates.

Schaefer, E. S., \& Edgerton, M. (1985). Parent and child correlates of parental modernity. In. I. E. Sigel (Ed.), Parental belief systems: the psychological consequences for children (pp. 287-318). Hillsdale, NJ: Lawrence Erlbaum Associates.

Segal, M. (1985). A study of maternal beliefs and val- ues within the context of an intervention program. In. I. E. Sigel (Ed.), Parental belief system: the psychological consequences for children. Hillsdale, NJ: Lawrence Erlbaum Associates.

Shin, E. J. (2011). The relationship among maternal parental beliefs, children's learning-related social skills and children's leadership. Unpublished master's thesis, Catholic University, Kyonggi, Korea.

Sigel, I. E. (1985). A conceptual analysis of beliefs. In. I. E. Sigel (Ed.), Parental belief systems: the psychological consequences for children (pp. 345-371). Hillsdale, NJ: Lawrence Erlbaum Associates.

Smith, M. H., Beaulieu, L. J., \& Seraphine, A. (1995). Social capital, place of residence and college attendance. Rural Sociology, 60(3), 363-381.

Yonezawa, S. (2000). Unpacking the black box of tracking decisions: critical tales of families navigating the course of placement process. In. M. G. Sanders (Ed.), Schooling students placed at risk: research, policy, practice in the education of poor and minority adolescents (pp. 109-140). Mahwah, NJ: Erlbaum.

Received September 29, 2012

Revised December 17,2012

Accepted December 17, 2012 